Article

\title{
A Route Choice Model for Capturing Driver Preferences When Driving Electric and Conventional Vehicles
}

\author{
Anders F. Jensen ${ }^{1}{ }^{\mathbb{D}}$, Thomas K. Rasmussen ${ }^{1}$ and Carlo G. Prato ${ }^{2, *}$ \\ 1 Department of Technology, Management and Economics, Technical University of Denmark, \\ 2800 Kgs Lyngby, Denmark; afjje@dtu.dk (A.F.J.); tkra@dtu.dk (T.K.R.) \\ 2 School of Civil Engineering, The University of Queensland, 4072 Brisbane, Australia \\ * Correspondence: c.prato@uq.edu.au; Tel.: +61-7-3365 1569
}

Received: 5 January 2020; Accepted: 4 February 2020; Published: 5 February 2020

\begin{abstract}
Battery Electric Vehicles (BEVs) play an important role in the needed transition away from fossil fuels and Internal Combustion Engine Vehicles (ICEVs). Although transport planning models and routing problem solutions exist for BEVs, the assumption that BEV drivers search for the shortest path while constraining energy consumption does not have any empirical basis. This study presents a study of actual route choice behavior of drivers from 107 Danish households participating in a large-scale experiment with BEVs and at the same time driving their ICEVs. GPS traces from 8968 BEV and 6678 ICEV routes were map matched to a detailed road network to construct observed routes, and a route choice model was specified and estimated to capture behavioral differences related to the vehicle type. The results reveal that drivers had a higher sensitivity to travel time and trip length when driving BEVs, and to route directness after receiving the BEV, regardless of vehicle type. The results suggest the need to revise the assumptions of transport planning models and routing problems for BEVs in order not to fail to predict what drivers will do by ignoring differences and similarities related to vehicle type.
\end{abstract}

Keywords: Battery Electric Vehicles; Internal Combustion Engine Vehicles; route choice behavior; driver preferences; discrete choice models; driving behavior; utility maximization; direct routes

\section{Introduction}

The growing need to reduce emissions from the transport sector and the dependence on fossil fuels is driving the significant efforts of governments to incentivize the market diffusion of Battery Electric Vehicles (BEVs). BEVs use chemical energy stored in rechargeable battery packs for propulsion, while Internal Combustion Engine Vehicles (ICEVs) transform the energy from the combustion of fuel (e.g., petrol, diesel) to propel their engine. The type of energy is different, as the one from the battery packs is cleaner than the one from the fuel combustion, and the storage of energy is different, as the capacity and the recharging times of the BEV battery packs are worse than the capacity and refueling times of the ICEV fuel tanks. In a nutshell, BEVs are more sustainable, but ICEVs are far more practical.

Recently, governments have promoted BEVs by designing investment programs, legislation pieces and taxation policies [1-8], while manufacturers have innovated battery technology to improve performance and also reduce the range anxiety that relates to the poor adoption of BEVs [9-13]. The design of programs and policies alongside the innovation in battery technology are expected to jolt the system and stimulate a future rapid BEV growth, as reflected in demand assessments predicting reasonable market shares by $2020[1,14,15]$ and conspicuous market shares by 2030-2050 [14,16-18]. However, the market penetration of BEVs has been lethargic because of high costs [9,19-21], significant 
limits in driving range [22,23], anxiety and uncertainty related to the driving range [10,24-26], notable deficiencies in public charging infrastructure [27-30], and specific battery issues such as limited charge cycle and questionable stability [31-34].

A higher market share of BEVs would change the landscape of transport networks towards a more sustainable future, but market share predictions have been generally incorrect. The market share predictions require an understanding of the actual behavior of travelers, which has been understudied in the literature, and, in particular, transport planning models and routing problem solutions would greatly benefit from modeling the actual on-road behavior of BEV drivers to improve the realism of the predictions. While studies exist on travel mode choices towards sustainable solutions (for a review, see [35]) and the electric vehicle routing problem (for a review, see [36,37]), their assumptions about the actual behavior of BEV drivers are not founded on empirical evidence. As there is no study about the actual behavior of BEV drivers, its underlying factors, and possible differences with respect to the route choice behavior of ICEV drivers, this study addresses this gap by proposing a route choice model (see Supplementary Materials) that captures the preferences of drivers who had the opportunity of driving both ICEVs and BEVs within a large-scale revealed preferences (RP) experiment. Specifically, this study provides empirical evidence that would be instrumental to improve the realism of transport planning models and routing problem solutions, and hence the predictions of BEV market shares.

The remainder of this paper is structured as follows. Section 2 illustrates the existing knowledge on transport planning models and routing problem solutions from the perspective of the hypotheses on route choice behavior of BEV drivers. Section 3 presents the materials, with details about data collection and processing, as well as methods, with insight into choice set generation and route choice model estimation. Section 4 describes the characteristics of the sample of routes and the estimates of the joint model of ICEV and BEV route choices. Section 5 provides a discussion of the results vis-à-vis the hypotheses from the literature, and Section 6 presents the conclusions and further research directions.

\section{Literature Review}

The review of related work focuses on transport planning models, and specifically traffic assignment models producing traffic predictions that affect the BEV market share predictions, and electric vehicle routing problems with an emphasis on the hypotheses about the route choice behavior of BEV drivers. With the purpose of keeping the focus on the need for empirical evidence about the on-road behavior of BEV drivers, as well as maintaining this manuscript to a reasonable length, the review does not focus on planning models and routing problems not concerning BEVs.

The literature on the electric vehicle routing problem focused initially on energy consumption and hypothesized that BEV drivers' route choice behavior consisted of the search for the most energy efficient path both without [38-40] and with the option of recharging batteries in battery swap stations [41-44]. A traffic assignment model then quantified the relations between travel patterns and energy consumption rates, while assuming that BEV drivers would exhibit the same route choice behavior of ICEV drivers [45].

Then, the literature on traffic assignment models and routing problems for BEVs concentrated on constrained path-based assignment and hypothesized that the route choice behavior of BEV drivers consisted of the search for paths within a certain distance threshold from the shortest one. A multi-class traffic assignment model considered BEVs as a vehicle class alongside ICEVs and imposed constraints to paths in the form of a distance limitation to the BEVs' equilibrium routes [46]. An extension to the model included choices of destination and parking, but the path-constrained assignment model remained unaltered [47]. Another extension to the model assumed different cost functions for BEVs and ICEVs in that the former included the recharging time alongside the travel time that was minimized for both classes [48]. Recent models considered stochasticity in trip chains and hence path choices as a function of heterogeneous range anxiety among travelers $[49,50]$.

Recently, the literature on traffic assignment models and routing problems for BEVs focused on recharging and hypothesized that the route choice behavior of BEV drivers consisted of the search 
for the path combining the shortest distance and the shortest recharging time. Initially, charging was considered available only at the origin or the destination of the trips in a network equilibrium model where flows were affected by the electric-charging price [51]. An extension to the model limited the recharging at the destination [28], in line with the optimal deployment of public charging stations, assuming that drivers would jointly select the route and destination on the basis of the charging prices at the destination [52]. Recharging capabilities were also considered in a network equilibrium model of BEVs where the set of usable paths was defined according to the energy consumption, but the cost function included only the travel time [53]. Risk attitudes towards range were included in a model based on the shortest path problem with non-additive cost, although without considering charging behavior during travel [54]. A node for the recharging requirement was also considered in a traffic assignment model of BEVs where the cost function included the energy consumption [55]. Additionally, a user equilibrium model where drivers could swap batteries at predetermined stations was formulated [56]. Lately, an optimization model was presented where drivers minimized travel time and charging costs to decide their route plan to charging stations [57].

All these models hypothesized that BEV drivers select the shortest path on the basis of a cost function that is usually a combination of travel time and, possibly, recharging time. Realistically, this hypothesis is rather restrictive when considering that it is not based on any empirical observation of the route choice behavior of BEV drivers. Accordingly, this study investigates revealed preferences of route choices when driving a BEV and compares them to the choices when driving an ICEV in order to provide the realism that is missing in all of these models because of simplistic assumptions that have no empirical foundation. It should be noted that an observational study of route choices between a highway and an arterial route exists and the effect of transient behavior on BEV energy consumption was captured [58]. However, the limitations of this study are quite substantial: (i) the observational study focused on only 39 trips with the purpose of feeding a simulation of 2000 trips for an hour; (ii) there were only two possible routes, one on a highway and another on an arterial road; (iii) the simulation relied on assumptions about route choice behavior and the study did not attempt to explain the behavior itself. It should also be noted that a behavioral model of route choices for BEV drivers actually exists and concludes that energy consumption, information about charging stations, vehicle attributes and range anxiety affect the route choices [59]. Although insightful, the limitations of this behavioral model are quite conspicuous: (i) the choices were elicited via a stated preferences (SP) experiment where the survey participants could only consider the factors that were a priori hypothesized to be relevant to their choices; (ii) the survey participants were unrealistically assumed to have complete information about available routes, their travel times, their battery level at the beginning of the imaginary trip, and the location of the charging stations; (iii) the survey participants were unrealistically assumed to experience range anxiety when they did not even drive during the experiment; (iv) most importantly, the survey participants were ICEV drivers in real life without any experience of driving BEVs.

This study overcomes the limitations in existing studies by proposing an RP study of route choice behavior from a large-scale BEV demonstration project that was conducted in Denmark. Detailed GPS traces were collected for each trip done by the participants while driving both BEVs and ICEVs and were matched to weather information. Then, map matching to the digitalized Danish road network allowed us to calculate the level-of-service variables for the trips while also adding the weather data and the household characteristics of the participants. Alternatives were then generated by a doubly stochastic generation algorithm. Subsequently, route choice models were specified and estimated jointly to capture the differences in the route choice behavior while driving BEVs and ICEVs, including possible differences in preferences while driving ICEVs before and during the BEV experiment. The large amount of data collected in the experiment and the state-of-the-art choice models estimated in this study provide the missing empirical evidence about route choice behavior of BEV drivers that might confirm or reject the aforementioned hypotheses in the existing literature. 


\section{Materials and Methods}

This study focused on the actual behavior of BEV drivers and hence the methodology consisted of (i) data collection, (ii) data processing, (iii) route choice set generation and (iv) route choice model estimation. It should be noted that (i) the data collection of thousands of routes is a major novelty in the literature focusing on BEV users' behavior, (ii) route choice analysis required the map matching of GPS traces and (iii) route choice behavior was estimated in a typical two-stage process (for a review, see [60]). Details about each step of the methodology for this study are presented in the following subsections.

\subsection{Data Collection}

The data were collected from December 2011 to February 2014 within a large demonstration project focusing on several aspects of BEV user behavior. The recruitment for the experiment was voluntary by applying online and submitting household sociodemographic information. Initial screening for being part of this study focusing on route choice behavior was that the household (i) owned at least one ICEV prior to the study and (ii) had a dedicated parking space available for the home charger installation. Final selection for being part of the study involved a random draw from the households fulfilling the criteria while covering a broad representation of the Danish population (for more details, please refer to $[61,62])$.

According to the study design, a BEV was provided to each household over a three-month period, and then the vehicle was assigned to a different household. Given the availability of 198 BEVs, data from 1578 households were collected with the aim of covering heterogeneity in the socioeconomic characteristics of the households, the seasons of their driving and the weather conditions.

Each participating household received either a Peugeot iOn, a Citroën C-Zero or a Mitsubishi ImiEV, which are very similar small-size BEVs with room for 4 to 5 passengers and limited luggage space. The standard driving range of the three vehicles is $150 \mathrm{~km}$, but analysis of the data revealed that only $7 \%$ of the vehicles could have covered the declared range based on the actual energy consumption [61]. A home charger was installed for each household and access to public charging infrastructure (including $3.7 \mathrm{~kW}$ AC and $50 \mathrm{~kW}$ DC chargers) was available in most of the country. It should be noted that the households did not pay for the BEV or the home charger, but they paid for the home charging consumption of electricity during the experiment. Moreover, the households were encouraged to use the BEV as their primary vehicle during the three months of availability for two reasons: (i) to increase the amount of information from driving the BEVs; (ii) to limit the variability in the data for the same household from multiple drivers participating in the experiment.

As every household owned an ICEV prior to the study, the trips with that vehicle were recorded with a GPS device for one month before and one month after the household received the BEV in order to obtain a baseline behavior. A GPS device was also mounted on the BEVs so that data included all the trips of the households with both types of vehicle over the duration of the experiment. Given budget restrictions, however, only 107 households from 13 different Danish municipalities had their ICEV trips recorded with a GPS device. As this study aimed at understanding the actual behavior of BEV drivers while comparing it with the behavior of the same drivers at the wheel of their ICEV, these 107 households comprised the sample considered in this study.

\subsection{Data Processing}

The GPS traces were matched to the NAVTEQ street network that consists of 636,243 links covering the entire country and belonging to all road classes from large highways to minor local roads. The high level of detail of the NAVTEQ network was necessary to allow for the possibility that BEV users might use smaller roads with lower speeds in order to save energy.

A filtering process was applied after the map matching according to the following criteria: (i) observations with a length inferior to $1 \mathrm{~km}$ were removed because of the likely problem of finding alternative routes in the choice set generation process; (ii) observations where over $20 \%$ of the route was 
filled via shortest path searches covering gaps in the traces were removed because of the uncertainty about the actual behavior of the driver. After map matching and filtering, the dataset consisted of $11,928 \mathrm{BEV}$ and 8679 ICEV observed routes from 107 households. It should be noted that the routes with the ICEV were observed in the month before and after the BEV was received, while the routes with the BEV were observed for the entire three-month period of the trial.

For each observed route, data from the local weather stations provided information about the weather at the time and day of departure including precipitation, wind, temperature and visibility. Figures 1 and 2 illustrate the spatial distribution of the observed routes to show that they cover a large part of the network over the 13 municipalities that are distributed across the whole country. Figure 1 shows the distribution over Denmark, where intuitively the most populated eastern island also had most of the observations, while Figure 2 zooms in on the Copenhagen Region.

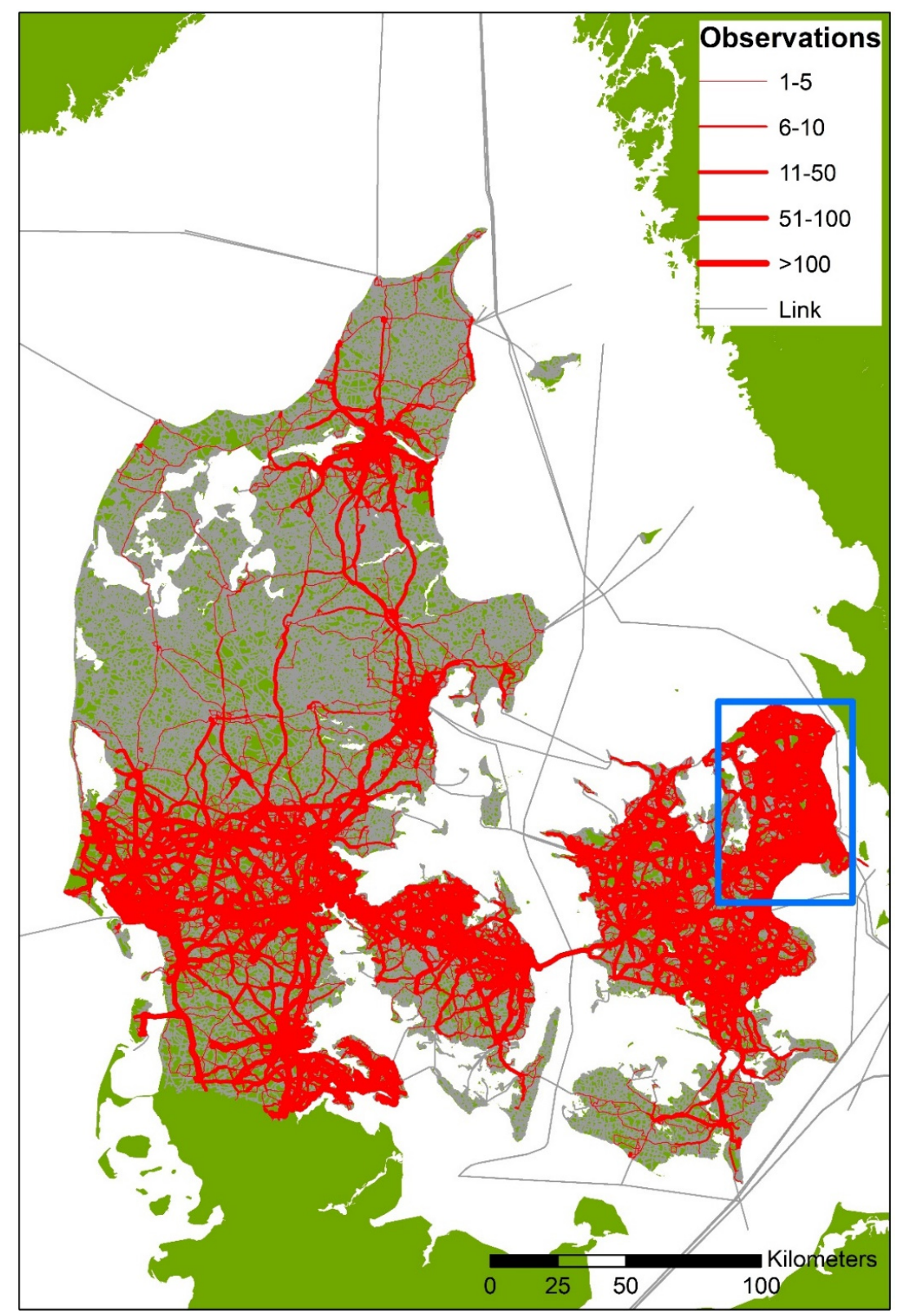

Figure 1. Spatial distribution of the observed routes (ICEV or BEV) across Denmark. 


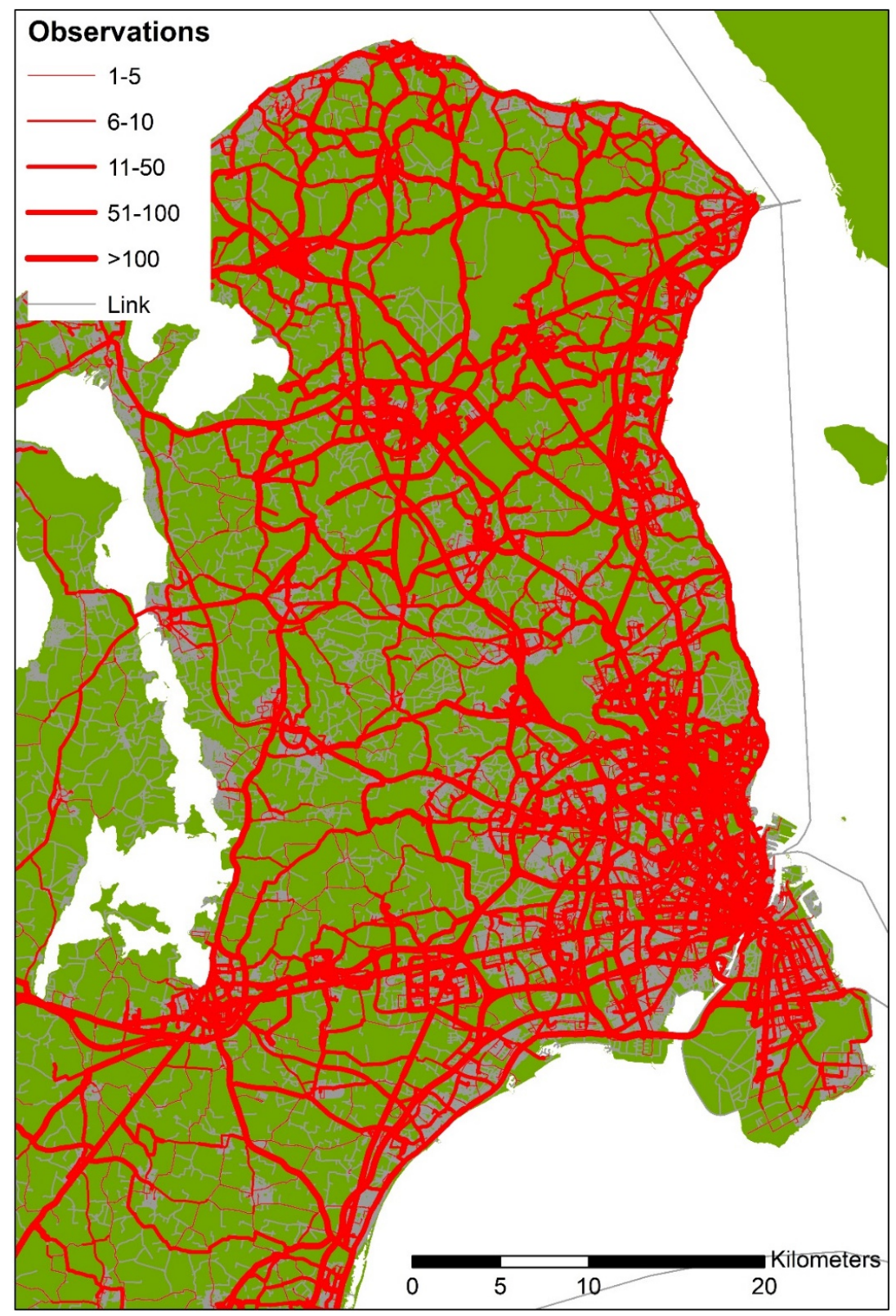

Figure 2. Spatial distribution of the observed routes (ICEV or BEV) in the Copenhagen Region.

\subsection{Choice Set Generation}

Route choice behavior was modeled with a state-of-the-art two-stage approach consisting of choice set generation to create routes that are alternative to the observed one, and then route choice model specification and estimation (for details, see [60,63]).

The first stage consisted of a doubly stochastic generation process $[63,64]$ that generated a choice set consisting of a maximum of 100 unique alternatives for each observed route. The selection of this generation process was motivated by the ability of the generation function to account for distance and free-flow travel time while the double stochasticity captured errors in the perception of costs by the drivers as well as heterogeneity in the sensitivity to costs across the drivers. The specification of the distributions of the error term and the parameters of distance and free flow travel time were adopted from the calibrated Danish National Transport Model.

Following the generation of the alternatives, a filtering process was applied according to the following criteria: (i) observations were removed if they contained only the chosen route and no alternative route; (ii) observations were removed if they did not include any route that was overlapping 
at least $80 \%$ with the observed one. After choice set generation and filtering, the dataset consisted of 8968 BEV and 6678 ICEV observed routes from 107 households. Prior to the specification and estimation of the route choice model, the following level-of-service attributes were calculated for each alternative route within the choice set of each observation: (i) travel time, (ii) trip length, (iii) number of left turns, and (iv) number of right turns. Moreover, the attributes of the households and the trips were also associated with each route for the purpose of evaluating interaction effects with the level-of-service attributes of the routes.

\subsection{Route Choice Model}

The second stage consisted of the specification and estimation of mixed path size correction logit (MPSCL) models for capturing the route choice behavioral preferences of drivers [63,65]. Three models were specified for the three different periods where the drivers used different vehicles: (i) a model for the ICEV1 period where they were driving ICEVs prior to the experiment; (ii) a model for the $B E V$ period where they were testing the BEVs in the experiment; (iii) a model for the ICEV2 period where they were driving their ICEVs after receiving (and having available) the BEV.

For each period $T$ (where $T$ is equal to either ICEV1, BEV or ICEV2), each household $k$ (where $k=1, \ldots, K$ and $K$ is the number of households) was observed in route choice situations $n$ (where $n=1, \ldots, N_{k}^{T}$ and $N_{k}^{T}$ is the number of observations for household $k$ in period $T$ ). The three models were specified with linear-in-parameter systematic utility functions $\left(V_{k n j}{ }^{I C E V 1}, V_{k n j}{ }^{B E V}\right.$, and $V_{k n j}{ }^{I C E V 2}$, respectively) for each route $j$ in the choice set generated for observation $n$ of household $k$ in period $T$ :

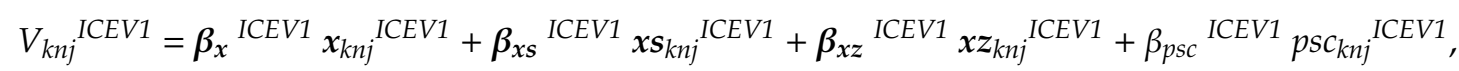

$$
\begin{aligned}
& V_{k n j}{ }^{B E V}=\boldsymbol{\beta}_{x}{ }^{B E V} \boldsymbol{x}_{k n j}{ }^{B E V}+\boldsymbol{\beta}_{x s}{ }^{B E V} \boldsymbol{x s}_{k n j}{ }^{B E V}+\boldsymbol{\beta}_{x z}{ }^{B E V} \boldsymbol{x}_{k n j}{ }^{B E V}+\beta_{p s c}{ }^{B E V} p s c_{k n j}{ }^{B E V},
\end{aligned}
$$

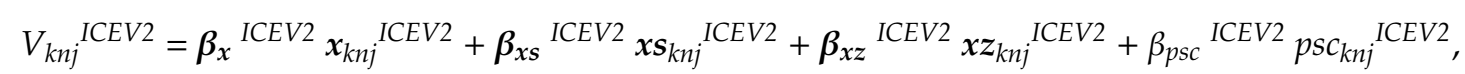

where $x_{k n j}{ }^{T}$ are the vectors of the attributes of route $j$ of observation $n$ for household $k$ in period $T, x s_{k n j}{ }^{T}$ are the vectors of the interaction effects between the route attributes and the elements of the vector $s_{k}$ of socioeconomic characteristics of household $k, x z_{k n j}{ }^{T}$ is the vector of interaction effects between the route attributes and the elements of the vector $z_{k n}{ }^{T}$ of environmental and vehicle related characteristics of observation $n$ for household $k$ in period $T$ (e.g., weather, level of battery charge at time of departure), $p s c_{k n j}{ }^{T}$ are the path size correction factors capturing the similarity between alternative routes $j$ within the choice set generated for observation $n$ of household $k$ in period $T, \beta_{p s c}{ }^{T}$ are the related parameters to be estimated, and $\boldsymbol{\beta}_{x}{ }^{T}, \beta_{x s}{ }^{T}$ and $\boldsymbol{\beta}_{x z}{ }^{T}$ are the vectors of the parameters to be estimated.

As the motivation of this study is the understanding of possible differences in the route choice behavior while driving ICEVs and BEVs, the focus was on the differences between the parameter estimates of the three models. However, estimating the three route choice models separately and comparing their parameter estimates would have been incorrect, since the estimates of generic parameters $\beta_{x}^{T}$ for variable $x$ (either a route attribute or an interaction effect) and period T are actually the product $\mu_{x}{ }^{T} \beta_{x}{ }^{T}$, where the scale parameters $\mu_{x}{ }^{T}$ of each of the three models would be normalized to one because they are neither identifiable within a particular data source relative to period $T$, nor separable from the generic utility parameters $\beta_{x}^{T}$ [66]. Accordingly, the three route choice models were estimated jointly and the scale parameters of the three models were then considered in the estimation to capture the actual differences between them and consequently evaluate the differences between the parameter estimates $[67,68]$.

The estimation of the joint models followed the same process proposed for modelling jointly stated and revealed preferences data in the context of Logit [67-70] and Mixed Logit models [71-73]. For the three periods, the random utility functions $U_{k n j}{ }^{I C E V 1}, U_{k n j}{ }^{B E V}$, and $U_{k n j}{ }^{I C E V 2}$ were then written as:

$$
U_{k n j}^{I C E V 1}=\mu^{I C E V 1} V_{k n j}^{I C E V 1}+\varepsilon_{k n j}^{I C E V 1},
$$




$$
\begin{gathered}
U_{k n j}{ }^{B E V}=\mu^{B E V} V_{k n j}{ }^{B E V}+\varepsilon_{k n j}{ }^{B E V}, \\
U_{k n j}{ }^{I C E V 2}=\mu^{I C E V 2} V_{k n j}{ }^{I C E V 2}+\varepsilon_{k n j}{ }^{I C E V 2},
\end{gathered}
$$

where the error terms $\varepsilon_{k n j}{ }^{I C E V 1}, \varepsilon_{k n j}{ }^{B E V}$ and $\varepsilon_{k n j}{ }^{I C E V 2}$ were assumed to be identically and independently Gumbel distributed, and their variances represent the different levels of random noise in the data that are captured by their respective scale parameters $\mu^{I C E V 1}, \mu^{B E V}$ and $\mu^{I C E V 2}$. Note that in this joint model, all the estimated parameters were scaled by the unknown scale parameter $\mu^{B E V}$ that was not identifiable and was then normalized to one. Note also that some of the parameters might be specified as generic across periods if, once the scale ratio was estimated, they were statistically similar.

The path size correction $p s c_{k n j}{ }^{T}$ captured the similarity across alternative routes within choice set $C_{k n}{ }^{T}$ for observation $n$ of household $k$ in period $T$, and was defined as [65]:

$$
p s c_{k n j}{ }^{T}=-\Sigma \mathrm{a} \in \Gamma_{k n j}{ }^{T}\left(\left(L_{a} / L_{k n j}{ }^{T}\right) \ln \Sigma j \in C_{k n j}{ }^{T}\left(\delta_{a j}\right)\right)
$$

where $L_{k n j}{ }^{T}$ is the length of route $j$ generated for observation $n$ of household $k$ in period $T, L_{a}$ is the length of link $a, \Gamma_{k n j}{ }^{T}$ is the set of links belonging to route $j$, and $\delta_{a j}$ captures the link-path relation, as it is equal to 1 if link $a$ belongs to route $j$ and 0 otherwise.

In this study, some elements of the vectors $\beta_{x}{ }^{T}, \beta_{x s}{ }^{T}$ and $\beta_{x z}{ }^{T}$ of the parameters to be estimated were randomly distributed with probability density function $f(\beta \mid \theta) d \beta$ in order to account for preference heterogeneity. The probability $P_{k n j}{ }^{T}$ for observation $n$ of household $k$ in period $T$ to have chosen route $i$ does not have a closed-form and requires integration over the distribution of the random parameters within the deterministic utilities $V_{k n j}^{T}$ for each period:

$$
P_{k n j}{ }^{T}=\int\left(\exp \left(\mu^{T} V_{k n i}{ }^{T}\right) /\left(\Sigma j \in C_{k n j}{ }^{T} \exp \left(\mu^{T} V_{k n j}{ }^{T}\right)\right) f(\beta \mid \theta) d \beta,\right.
$$

Consequently, the maximization of the log-likelihood function $L L$ required simulation for the estimation of the parameters:

$$
S L L=\Sigma_{\mathrm{T}} \Sigma_{\mathrm{k}} \Sigma_{\mathrm{n}} \Sigma_{\mathrm{i}} \in C_{k n j}{ }^{T}\left\{d _ { k n i } { } ^ { T } \operatorname { l n } \left\{1 / \mathrm{R} \Sigma_{\mathrm{r}}\left(\exp \left(\mu^{T} V_{k n i, r}{ }^{T}\right) /\left(\Sigma j \in C_{k n j}{ }^{T} \exp \left(\mu^{T} V_{k n j, r}{ }^{T}\right)\right]\right\}\right.\right.
$$

where SLL is the simulated log-likelihood, $d_{k n i}{ }^{T}$ is an indicator that is equal to 1 if route $i$ was the observed route for observation $n$ of household $k$ in period $T$ (and 0 otherwise), and $r$ is one of $R$ draws from the densities of the random parameters that were considered in the simulation. It should be noted that the choices were assumed to be correlated across household, namely the parameters were restricted to not vary across different observations of the same household. The simulated log-likelihood function was coded in Python Biogeme [74] and the simulation generated random draws via the Modified Latin Hypercube Sampling Method [75].

\section{Results}

\subsection{Generated Choice Sets}

The choice set generation procedure and subsequent filtering resulted in a total of 6678 observed routes in the ICEV periods and 8968 observed routes in the BEV period. Figure 3 illustrates the cumulative distribution of observations at various thresholds for the minimum overlap with the observed route (for a definition of overlap, see [60]). It can be seen that the doubly stochastic choice set generation reproduced over $75 \%$ of the observed routes for both datasets with an $80 \%$ overlap threshold. Moreover, the procedure replicated link by link about $50 \%$ of the observed routes after the filtering, an impressive feature considering the level of detail of the network. These results indicate that the choice set generation method was successful in reproducing the observed routes within the generated choice sets. 


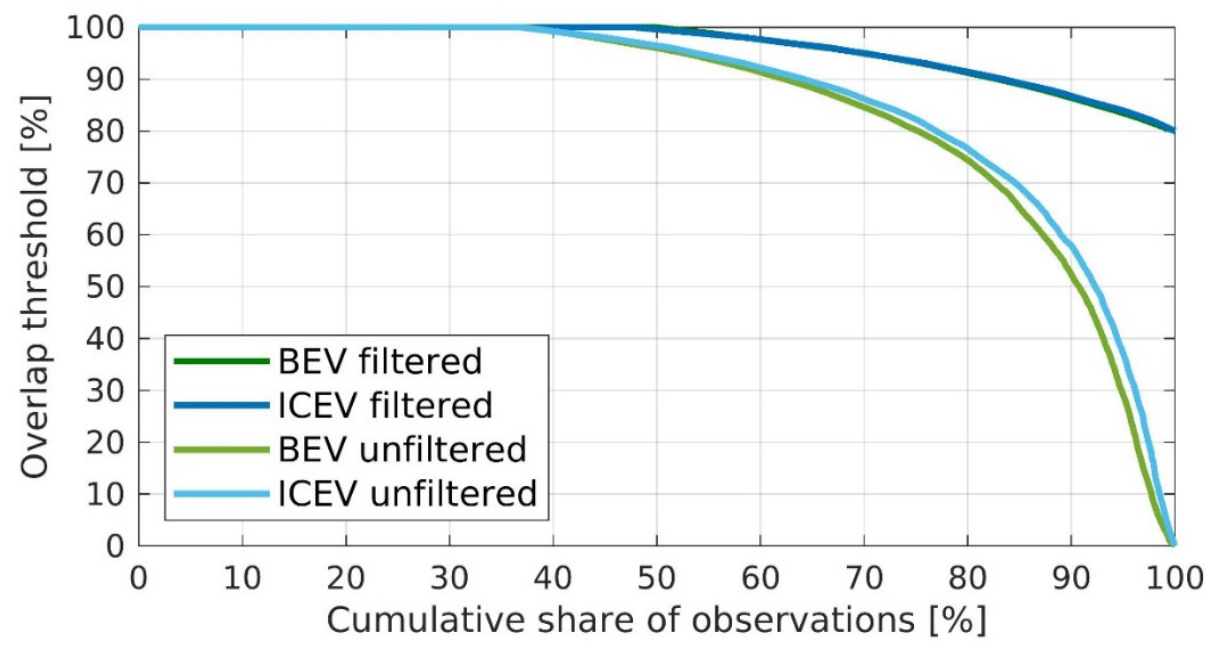

Figure 3. Coverage of observed routes.

The distribution of the choice set size for the filtered observations is shown in Figure 4. The number of unique routes covers the whole range, from 2 to 100, and in general large choice sets were generated. A visual inspection for a large number of observations suggested that the large number of alternatives is not due to the generation of implausible routes, but rather to the very disaggregate network structure. In addition to the generation of the observed route and some relevant considerably different alternatives, the disaggregate network structure implies the generation of several alternatives that are small deviations to the observed route.

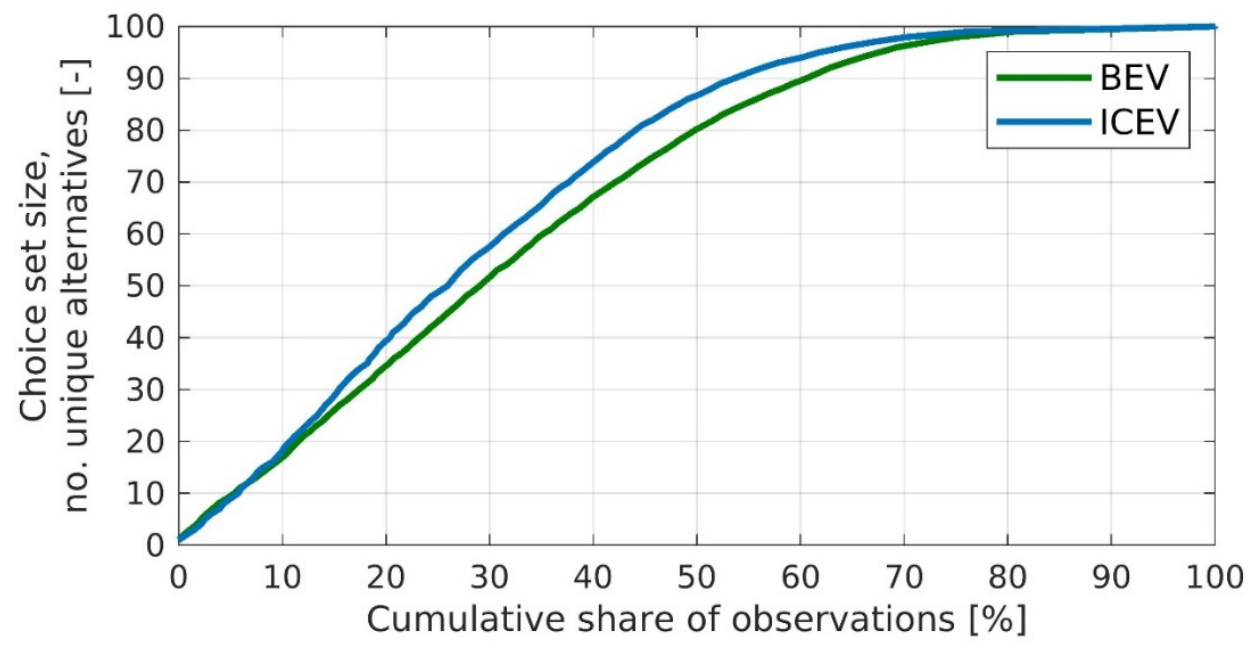

Figure 4. Distribution of the choice set sizes.

Table 1 lists the characteristics of the observed routes as well as the generated alternatives. When looking at the observed routes, clearly the BEV trips were shorter in distance and time when compared to the ICEV trips. Moreover, as soon as the BEV became available to the household, fewer trips were done with the ICEV, but they were longer than the previous ones. This suggests that households would drive the ICEV for longer trips to avoid possible limitations because of the BEV driving range. This also indicates that, although the households were encouraged to use the BEV as their primary vehicle, they maintained the use of the ICEV for a large portion of their trips. 
Table 1. Sample description.

\begin{tabular}{|c|c|c|c|c|c|c|}
\hline & \multirow[b]{2}{*}{ Variable Description } & \multirow[b]{2}{*}{ Variable } & \multicolumn{2}{|c|}{ Observed } & \multicolumn{2}{|c|}{ Alternatives } \\
\hline & & & Mean & Std Dev & Mean & Std Dev \\
\hline \multirow{9}{*}{ ICEV1 (4175 obs) } & Travel time (min) & time & 14.73 & 16.07 & 19.89 & 20.23 \\
\hline & Number of left turns & leftturns & 3.43 & 2.99 & 8.35 & 6.33 \\
\hline & Number of right turns & rightturns & 4.80 & 3.90 & 9.94 & 7.31 \\
\hline & Household lives in an urban area & hhurban & 0.10 & 0.29 & & \\
\hline & $\begin{array}{l}\text { Household head's income is above } \\
\text { 750.000DKK }\end{array}$ & highinc & 0.25 & 0.44 & & \\
\hline & Household head is male & hhmale & 0.53 & 0.50 & & \\
\hline & $\begin{array}{c}\text { Precipitation at day of departure is } \\
\text { above } 9 \mathrm{~mm}\end{array}$ & avgrain & 0.14 & 0.34 & & \\
\hline & $\begin{array}{c}\text { Observed trip departs during } \\
\text { morning peak }\end{array}$ & mornpeak & 0.13 & 0.34 & & \\
\hline & $\begin{array}{c}\text { Sunshine at day of departure is } \\
\text { above } 36 \mathrm{~min}\end{array}$ & avgsun & 0.25 & 0.44 & & \\
\hline \multirow{11}{*}{ BEV (8968 obs) } & Travel time (min) & time & 9.58 & 7.73 & 12.65 & 8.85 \\
\hline & Length $(\mathrm{km})$ & length & 11.32 & 10.63 & 14.58 & 11.92 \\
\hline & Number of left turns & leftturns & 3.43 & 2.95 & 7.67 & 4.95 \\
\hline & Number of right turns & rightturns & 4.81 & 3.86 & 9.21 & 5.77 \\
\hline & $\begin{array}{l}\text { Battery state-of-charge at tripstart } \\
\qquad(\%)\end{array}$ & bat_start & 75.02 & 20.00 & & \\
\hline & Household lives in an urban area & hhurban & 0.11 & 0.31 & & \\
\hline & $\begin{array}{l}\text { Household head's income is above } \\
750.000 \mathrm{DKK}\end{array}$ & highinc & 0.26 & 0.44 & & \\
\hline & Household head is male & hhmale & 0.56 & 0.50 & & \\
\hline & $\begin{array}{c}\text { Precipitation at day of departure is } \\
\text { above } 9 \mathrm{~mm}\end{array}$ & avgrain & 0.11 & 0.31 & & \\
\hline & $\begin{array}{c}\text { Observed trip departs during } \\
\text { morning peak }\end{array}$ & mornpeak & 0.09 & 0.29 & & \\
\hline & $\begin{array}{c}\text { Sunshine at day of departure is } \\
\text { above } 36 \mathrm{~min}\end{array}$ & avgsun & 0.22 & 0.41 & & \\
\hline \multirow{10}{*}{ ICEV2 (2503 obs) } & Travel time (min) & time & 18.27 & 19.09 & 24.30 & 23.25 \\
\hline & Length $(\mathrm{km})$ & length & 20.03 & 27.13 & 25.23 & 29.74 \\
\hline & Number of left turns & leftturns & 3.76 & 3.34 & 9.07 & 7.22 \\
\hline & Number of right turns & rightturns & 5.08 & 4.19 & 10.71 & 8.24 \\
\hline & Household lives in an urban area & hhurban & 0.06 & 0.24 & & \\
\hline & $\begin{array}{l}\text { Household head's income is above } \\
750.000 \mathrm{DKK}\end{array}$ & highinc & 0.37 & 0.48 & & \\
\hline & Household head is male & hhmale & 0.55 & 0.50 & & \\
\hline & $\begin{array}{l}\text { Precipitation at day of departure is } \\
\text { above } 9 \mathrm{~mm}\end{array}$ & avgrain & 0.14 & 0.35 & & \\
\hline & $\begin{array}{c}\text { Observed trip departs during } \\
\text { morning peak }\end{array}$ & mornpeak & 0.14 & 0.34 & & \\
\hline & $\begin{array}{l}\text { Sunshine at day of departure is } \\
\text { above } 36 \mathrm{~min}\end{array}$ & avgsun & 0.21 & 0.41 & & \\
\hline
\end{tabular}

Table 1 shows that there are differences between the observed and generated routes in terms of average travel time, number of turns and trip length. It appears that the chosen routes are shorter and more direct than the generated alternatives, and while that might be expected for the trips in the $\mathrm{BEV}$ period, as the literature hypothesizes a more direct travel as a result of range anxiety and energy saving, it is interesting that it applies also to the trips in both ICEV periods. Interestingly, the trips in the BEV period are shorter than ICEV trips in terms of time and distance, but more comparable to ICEV ones in terms of number of turns and hence directness.

It should be noted that the socio-economic characteristics of the household as well as weather variables are included. Precipitation above $9 \mathrm{~mm}$ refers to observations with precipitation above average for the day of the trip, and sunshine above $36 \mathrm{~min}$ refers to the $25 \%$ of observations with mostly sunshine during the day of the trip. Very limited differences were observed with respect to these characteristics for the trips in the three periods. The socio-economic characteristics of the households in the experiment were collected, and it should be noted that the differences in the values for the three periods indicate only differences in the use of the technology (as based on number of trips and not number of individuals), as previously analyzed in detail [62]. 


\subsection{Route Choice Model Estimates}

The specification testing of the joint route choice models initially involved the estimation of a base model with the two parameters for travel time and length distributed according to a lognormal distribution, and the two parameters for left and right turns distributed according to a normal distribution. We estimated technology-specific parameters for all attributes with the exception of travel time, given the need for at least one parameter to be kept generic across the datasets of BEV and ICEV routes. We also examined possible interactions for each of the four attributes with the household and temporal characteristics of the trips and hence created technology specific parameters.

After considering the estimated parameters in the joint models that were significant at least at the 0.05 level, we tested for their differences across different groups of observations. We also estimated each interaction effect separately to avoid multi-collinearity issues, and we retained the interaction effects that were significant at the 0.05 level. Lastly, we retained in the model all the significant generic and technology-specific parameters (it should be noted that the technology-specific parameters were not different for the two ICEV periods). A total of 18 parameters were estimated in the final joint mixed path-size correction logit models, with the following specification of the utility functions (scale parameters for the ICEV1 and ICEV2 periods were also estimated with respect to the normalized scale parameter for the BEV period):

$$
\begin{aligned}
& V_{k n j}{ }^{B E V}=\beta_{t} t_{k n j}{ }^{B E V}+\beta_{l} l_{k n j}{ }^{B E V}+\beta_{t p r e c} \text { tprec }_{k n j} B E V+\beta_{l s u n} l_{s u n}{ }_{k n j} B E V+ \\
& \beta_{\text {turncity }} \text { turncity }_{k n j} B E V+\beta_{\text {lturn }} B E V \text { lturn }_{k n j} B E V+\beta_{\text {rturn }} B E V \operatorname{rturn}_{k n j} B E V+\beta_{p s c} p^{B c c_{k n j}} B E V \text {, }
\end{aligned}
$$

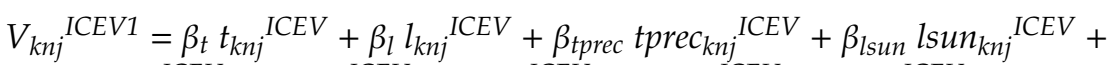

$$
\begin{aligned}
& \beta_{\text {turncity }} \text { turncity }_{k n j} \text { ICEV }+\beta_{\text {lturn }} \text { ICEV } \text { lturn }_{k n j} \text { ICEV }+\beta_{\text {rturn }} \text { ICEV rturn } \text { rnj }^{\text {ICEV }}+\beta_{p s c} \text { sSc }_{k n j} \text { ICEV , } \\
& V_{k n j}{ }^{I C E V 2}=\beta_{t} t_{k n j}{ }^{I C E V}+\beta_{l} l_{k n j}{ }^{I C E V}+\beta_{\text {tprec }} \text { tprec }_{k n j}{ }^{I C E V}+\beta_{\text {lsun }} \text { lsun }_{k n j} \text { ICEV }+ \\
& \beta_{\text {turncity }_{\text {turncity }} \text { IICEV }}+\beta_{\text {lturn }} \text { ICEV } \text { lturn }_{k n j} \text { ICEV }+\beta_{\text {rturn }} \text { ICEV rturn } \text { rnj }^{\text {ICEV }}+\beta_{p s c} \text { psc }_{k n j} \text { ICEV , }
\end{aligned}
$$

where, for each technology $T, t_{k n j}{ }^{T}$ is the travel time, $l_{k n j}{ }^{T}$ is the trip length, $l t u r n_{k n j}{ }^{T}$ is the number of left turns, and $r t u r n_{k n j}{ }^{T}$ is the number of right turns. Also, tprec $k n j{ }^{T}$ is the interaction term between travel time and precipitation, $l s u n_{k n j}{ }^{T}$ is the interaction term between trip length and sunshine, and $t u r n c i t y_{k n j}{ }^{T}$ is the interaction term between turns and city location. Lastly, $p s c_{k n j}{ }^{T}$ is the path correction factor for each alternative route in the choice set. The related parameters are either generic or specific according to the specification testing, and it should be noted that $\beta_{t}$ and $\beta_{l}$ are lognormally distributed, while $\beta_{\text {lturn }}{ }^{B E V}, \beta_{\text {rturn }}{ }^{B E V}, \beta_{\text {lturn }}$ ICEV and $\beta_{\text {rturn }}{ }^{\text {ICEV }}$ are normally distributed.

Table 2 presents the estimates of the best model specification. The comparison between parameter estimates requires us to consider the differences between the scale parameters, which were statistically equal when comparing the ones for the BEV and the ICEV1 periods, and statistically different when likening the ones for the BEV and ICEV2 periods. These estimates show that the BEV and ICEV1 datasets contain the same amount of noise, while the ICEV2 dataset contains a higher amount of noise since the variance of the error term is higher than that of the other two datasets. Moreover, these estimates enable us to compare the ratios between the $\mu^{T} \beta_{x}{ }^{T}$ products for the different periods, keeping in mind that having the same generic parameters while also having different scale parameters implies a difference in the preferences of drivers.

When looking at the four main attributes, the parameter estimates show that drivers do indeed minimize travel time, trip length, number of left turns and number of right turns. Heterogeneity was found to be significant for all four attributes, which implies that drivers have different perceptions when it comes to travel time and travel distance. 
Table 2. Estimates for the joint route choice models.

\begin{tabular}{|c|c|c|c|c|c|c|}
\hline & \multicolumn{2}{|c|}{ Generic } & \multicolumn{2}{|c|}{ ICEV } & \multicolumn{2}{|c|}{ BEV } \\
\hline & Estimate & $t$-Test & Estimate & $t$-Test & Estimate & $t$-Test \\
\hline Travel time (mean, min) & -2.130 & -6.34 & & & & \\
\hline Travel time (st. dev., min) & 1.890 & 8.74 & & & & \\
\hline Trip length (mean, $\log (\mathrm{km})$ ) & -10.800 & -16.79 & & & & \\
\hline Trip length (st. dev., $\log (\mathrm{km})$ ) & 8.060 & 11.90 & & & & \\
\hline Travel time $\times$ precipitation & 0.151 & 3.39 & & & & \\
\hline Trip length $\times$ sunshine & 0.106 & 2.42 & & & & \\
\hline Left turns (mean, number) & & & -0.694 & -9.58 & -0.545 & -24.42 \\
\hline Left turns (st. dev., number) & & & 0.280 & -7.71 & 0.281 & 12.13 \\
\hline Right turns (mean, number) & & & -0.434 & -8.56 & -0.278 & -15.99 \\
\hline Right turns (st. dev., number) & & & 0.234 & 6.93 & 0.163 & 10.91 \\
\hline Turns $\times$ city & -0.070 & -2.27 & & & & \\
\hline Path size correction & 1.020 & 12.89 & & & & \\
\hline Scale parameter $\mu^{I C E V 1}$ & & & 0.958 & $0.46^{*}$ & & \\
\hline Scale parameter $\mu^{I C E V 2}$ & & & 0.808 & $2.27 *$ & & \\
\hline Scale parameter for BEV $\left(\mu^{B E V}\right)$ & & & & & 1 & - \\
\hline Number of parameters & 19 & & & & & \\
\hline Number of observations & 15,646 & & & & & \\
\hline Log-likelihood at estimates & $-42,460$ & & & & & \\
\hline
\end{tabular}

Given the generic parameters for travel time and trip length, and factoring in the differences in the scale parameters between the BEV and the ICEV2 datasets, two considerations apply to the sensitivities to travel time and logarithm of trip length: (i) about the same sensitivities for the two attributes were obtained when comparing the BEV trips with the ICEV trips prior to receiving the BEV; (ii) about $20 \%$ lower sensitivity was estimated for ICEV after the BEV came available in the household.

Given the technology-specific parameters for the right and left turns, and considering the differences in the scale parameters, it looks like the sensitivity to turns is comparable between the BEV and the ICEV2 datasets, while it is about $25 \%$ higher for the ICEV1 dataset where the scale parameter does not compensate for the parameter difference. Basically, it appears that, on average, more direct routes (less turns) are searched for when driving the ICEV prior to the experiment, and then more direct routes are taken not only when testing the BEV, but also when using the ICEV at the same time. In other words, a change in preference towards less direct routes appears related to the BEV availability, but then the change seems linked also to the ICEV trips.

Interaction terms reveal that the sensitivity to travel time is reduced in the case of rainy weather and the sensitivity to trip length is lessened in the case of sunshine. Also, turns are penalized more in the city, possibly because route directness is more important in urban areas where there might be congestion. It should be noted that, because of the differences in the scale parameters, a higher variation is observed for these interaction terms when driving a $\mathrm{BEV}$, as again there is about a $20 \%$ higher sensitivity to the combination of attributes. Overall, the findings reveal the existence of some behavioral differences when driving a BEV or an ICEV, but also some similarities, in that drivers seem to appreciate directness more just because of the BEV availability, regardless of the vehicle they are driving.

\section{Discussion}

The observation of the route choices suggested that the first difference emerged when the BEV became available, namely households appeared to choose BEVs for shorter trips and ICEVs for longer ones. When considering that most electric vehicle routing problems were solved under the assumption that BEV drivers minimize energy consumption [38-40,42-44], and that transport planning models followed similar assumptions [52-56], this is not a trivial finding, since it suggests that it is more a matter of vehicle choice rather than route cost minimization according to a cost function that depends on the vehicle type. 
Model parameter estimates suggested that differences exist in the behavior on the road while driving the BEVs or the ICEVs. As expected, the minimization of travel time, trip length and number of turns is the behavior of choice, but empirical evidence shows that the relation with trip length is not linear in the attribute and captures the fact that the sensitivity to the driven distance varies between shorter and longer trips. Non-linearity with trip length has not been hypothesized in the existing transport planning models and routing problems. Also, heterogeneity exists for all attributes, a hypothesis that confirms differences in the perceptions of travel time and length, but this is rarely accounted for in traffic assignment models focusing on different degrees of range anxiety $[49,50]$.

Parameter estimates show that differences emerged when comparing BEV and ICEV driving. This empirical finding is not in line with the assumption that the route choice behavior is similar for BEVs and ICEVs [45], but confirms the hypothesis that BEV drivers might look for shorter and faster routes that potentially might be associated with the perception of lower energy consumption $[17,52]$. Clearly, only a very low number of studies appear in line with the empirical evidence from our study. Interestingly, the sensitivity to travel time and trip length emerged as higher for BEV driving when compared to ICEV driving, but only after the BEV was received. Conversely, the choice of more direct routes emerged as being lower for BEV driving with respect to ICEV driving prior to the experiment, and this behavior was actually independent of the type of vehicle, as comparable parameters were obtained for the ICEV driving while the experiment was running. This finding is also interesting as it suggests that the driving behavior did not change for the BEV with respect to the ICEV, but after using the BEV—for example, drivers changed their perception of turns when driving both types of vehicle, suggesting that existing models should not differentiate by vehicle technology, but by time when a new one is available at the household level.

Parameter estimates suggest also that weather and urban environment mitigated or exacerbated some of the sensitivity to time and distance, an aspect that is often neglected in traffic assignment models. An interesting aspect that emerged was that weather affects the sensitivity to travel time and trip length. Specifically, precipitation over the average relates to a lower sensitivity to travel time while sunshine over the average relates to a lower sensitivity to trip length. It was expected from the literature that BEVs are sensitivity to temperature [61,76], but that did not emerge as significant in terms of route choice preferences.

The empirical results suggest that considering constraints on the available paths [46-48] and accounting for heterogeneity $[43,44]$ are definitely hypotheses in line with the findings of this study, although unfortunately only a handful of studies appear to have formulated hypotheses in line with the empirical evidence from this study, and generally they seem to have formulated single hypotheses without covering all the different aspects that this study has uncovered.

\section{Conclusions}

On the basis of a substantial dataset and state-of-the-art methodology, this study presented a route choice study that elicited differences in the preference structures of drivers when driving BEVs rather than ICEVS. As the first large-scale RP study looking at actual route choices of BEV drivers, this study modelled the selection of thousands of routes after map matching them to a high-resolution network and generating plausible routes with advanced choice set generation techniques.

Arguably, a limitation of this study is that BEV technology has improved in recent years and mid-size models introduced in 2019 have a nominal range of $3 / 400 \mathrm{~km}$ on a full charge of battery. A longer range than the models in this study might imply that drivers do not adapt their route choice preferences when compared to driving their ICEVs to the same extent found in this study. However, the presented results are relevant for several reasons: (i) the high battery costs make companies launch models with smaller driving ranges (e.g., the newest Honda e has a nominal range of 220km [77]) as the models with larger driving range are only accessible to higher income households; (ii) the nominal driving range is still measured in laboratory conditions that make the actual driving range usually significantly lower [61]; (iii) even the higher end of driving ranges is still far from current ICEV driving 
ranges, and a recent analysis of Chinese customers revealed that the preferred driving ranges for BEVs and Plug-in Hybrid Vehicles (PHEVs) are around $50 \mathrm{~km} \mathrm{[78].}$

Accordingly, the major contribution of this study is the unique possibility to understand the difference in preferences when driving BEVs and ICEVs with a large-scale revealed preferences (RP) experiment. Clearly, the assumption of shortest path selection on the basis of a cost function that combines travel time and possibly recharging time is not appropriate when looking at the findings of this study, suggesting how the sensitivity to distance and time is heterogeneous and varies with the distance travelled as well as the directness of the route. Accordingly, future research should, on the one hand, look for more empirical evidence for constructing more realistic cost functions, and on the other hand embed these cost functions within traffic assignment models that would be far more correct in predicting route choice behavior of BEV as well as ICEV drivers.

Moreover, future traffic assignment models could consider a few adjustments: (i) an equilibrium solution could be found where vehicle classes should be flexible and the allocation of travelers to each class should depend on endogenously defined thresholds for travel time and distance; (ii) an equilibrium solution could be found where the choice sets would be equilibrated and the traffic assignment model would be consistent with the route choice behavior and include thresholds on travel costs (see [79,80]; (iii) the utility function for BEVs and ICEVs should take into account, at the very least, the different sensitivity to travel time, distance and route directness, which was instead considered equal in previous models; (iv) the classes of drivers should relate to the household owning a BEV rather than the individual driving either a BEV or an ICEV.

Supplementary Materials: The following are available online at http://www.mdpi.com/2071-1050/12/3/1149/s1, The route choice dataset for model estimation that was used in this study is attached.

Author Contributions: Conceptualization, A.F.J., T.K.R. and C.G.P.; methodology, A.F.J., T.K.R. and C.G.P.; data curation, A.F.J. and T.K.R.; writing-Original draft preparation, C.G.P.; writing-Review and editing, A.F.J., T.K.R.; supervision, C.G.P.; project administration, A.F.J. and T.K.R.; funding acquisition, A.F.J. and T.K.R. All authors have read and agreed to the published version of the manuscript.

Funding: This research was funded by the European Commission, grant "Green Emotion" and the Danish Council for Independent Research, grant "Using big data sources for the consistent estimation of next-generation route choice models".

Acknowledgments: We are grateful to four anonymous reviewers for the substantial contribution to improving the original version of this manuscript.

Conflicts of Interest: The authors declare no conflict of interest. Also, the funders had no role in the design of the study; in the collection, analyses, or interpretation of data; in the writing of the manuscript, or in the decision to publish the results.

\section{References}

1. Brady, J.; O'Mahony, M. Travel to work in Dublin: The potential impacts of electric vehicles on climate change and urban air quality. Transp. Res. Part D Transp. Environ. 2011, 16, 188-193. [CrossRef]

2. Bakker, S.; Trip, J.J. Policy options to support the adoption of electric vehicles in the urban environment. Transp. Res. Part D Transp. Environ. 2013, 25, 18-23. [CrossRef]

3. Zhang, X.; Xie, J.; Rao, R.; Liang, Y. Policy incentives for the adoption of electric vehicles across countries. Sustainability 2014, 6, 8056-8078. [CrossRef]

4. Bjerkan, K.Y.; Nørbech, T.E.; Nordtømme, M.E. Incentives for promoting battery electric vehicle (BEV) adoption in Norway. Transp. Res. Part D Transp. Environ. 2016, 43, 169-180. [CrossRef]

5. Cansino, J.M.; Sánchez-Braza, A.; Sanz-Díaz, T. Policy instruments to promote electro-mobility in the EU28: A comprehensive review. Sustainability 2018, 10, 2507. [CrossRef]

6. Lam, A.; Lee, S.; Mercure, J.F.; Cho, Y.; Lin, C.H.; Pollitt, H.; Chewpreecha, U.; Billington, S. Policies and predictions for a low-carbon transition by 2050 in passenger vehicles in East Asia: Based on an analysis using the E3ME-FTT Model. Sustainability 2018, 10, 1612. [CrossRef]

7. Kim, E.; Heo, E. Key drivers behind the adoption of electric vehicle in Korea: An analysis of the revealed preferences. Sustainability 2019, 11, 6854. [CrossRef] 
8. Li, W.; Long, R.; Chen, H.; Chen, F.; Zheng, X.; Yang, M. Effect of policy incentives on the uptake of electric vehicles in China. Sustainability 2019, 11, 3323. [CrossRef]

9. Kihm, A.; Trommer, S. The new car market for electric vehicles and the potential for fuel substitution. Energy Policy 2014, 73, 147-157. [CrossRef]

10. Franke, T.; Krems, J.F. Understanding charging behaviour of electric vehicle users. Transp. Res. Part F Traffic Psychol. Behav. 2013, 21, 75-89. [CrossRef]

11. Rezvani, Z.; Jansson, J.; Bodin, J. Advances in consumer electric vehicle adoption research: A review and research agenda. Transp. Res. Part D Transp. Environ. 2015, 34, 122-136. [CrossRef]

12. Fetene, G.M.; Kaplan, S.; Sebald, A.C.; Prato, C.G. Myopic loss aversion in the response of electric vehicle owners to the scheduling and pricing of vehicle charging. Transp. Res. Part D Transp. Environ. 2017, 50, 345-356. [CrossRef]

13. Kim, S.; Lee, J.; Lee, C. Does driving range of electric vehicles influence electric vehicle adoption? Sustainability 2017, 9, 1783. [CrossRef]

14. Lebeau, K.; van Mierlo, J.; Lebeau, P.; Mairesse, O.; Macharis, C. The market potential for plug-in hybrid and battery electric vehicles in Flanders: A choice-based conjoint analysis. Transp. Res. Part D Transp. Environ. 2012, 17, 592-597. [CrossRef]

15. Mendes Lopes, M.; Moura, F.; Martinez, L.M. Rule-based approach for determining the plausible universe of electric vehicle buyers in the Lisbon Metropolitan Area. Transp. Res. Part A Policy Pract. 2014, 59, $22-36$. [CrossRef]

16. Mabit, S.L.; Fosgerau, M. Demand for alternative-fuel vehicles when registration taxes are high. Transp. Res. Part D Transp. Environ. 2011, 16, 225-231. [CrossRef]

17. Traut, E.J.; Cherng, T.W.C.; Hendrickson, C.; Michalek, J.J. US residential charging potential for electric vehicles. Transp. Res. Part D Transp. Environ. 2013, 25, 139-145. [CrossRef]

18. Shim, D.; Kim, S.W.; Altmann, J.; Yoon, Y.T.; Kim, J.G. Key features of electric vehicle diffusion and its impact on the Korean power market. Sustainability 2018, 10, 1941. [CrossRef]

19. Lipman, T.E.; Delucchi, M.A. A retail and lifecycle cost analysis of hybrid electric vehicles. Transp. Res. Part D Transp. Environ. 2006, 11, 115-132. [CrossRef]

20. Wu, X.; Freese, D.; Cabrera, A.; Kitch, W.A. Electric vehicles' energy consumption measurement and estimation. Transp. Res. Part D Transp. Environ. 2015, 34, 52-67. [CrossRef]

21. Breetz, H.L.; Salon, D. Do electric vehicles need subsidies? Ownership costs for conventional, hybrid, and electric vehicles in 14 US cities. Energy Policy 2018, 120, 238-249. [CrossRef]

22. Egbue, O.; Long, S. Barriers to widespread adoption of electric vehicles: An analysis of consumer attitudes and perceptions. Energy Policy 2012, 48, 717-729. [CrossRef]

23. Peterson, S.B.; Michalek, J.J. Cost-effectiveness of plug-in hybrid electric vehicle battery capacity and charging infrastructure investment for reducing US gasoline consumption. Energy Policy 2013, 52, 429-438. [CrossRef]

24. Franke, T.; Neumann, I.; Bühler, F.; Cocron, P.; Krems, J.F. Experiencing range in an electric vehicle: Understanding psychological barriers. Appl. Psychol. 2012, 61, 368-391. [CrossRef]

25. Jensen, A.F.; Cherchi, E.; Mabit, S.L. On the stability of preferences and attitudes before and after experiencing an electric vehicle. Transp. Res. Part D Transp. Environ. 2013, 25, 24-32. [CrossRef]

26. Noel, L.; de Rubens, G.Z.; Sovacool, B.K.; Kester, J. Fear and loathing of electric vehicles: The reactionary rhetoric of range anxiety. Energy Res. Soc. Sci. 2019, 48, 96-107. [CrossRef]

27. Liu, J. Electric vehicle charging infrastructure assignment and power grid impacts assessment in Beijing. Energy Policy 2012, 51, 544-557. [CrossRef]

28. Zhang, T.; Boyles, S.; Waller, S.T. Modeling combined travel choices of electric vehicle drivers with a variational inequality network formulation. In Proceedings of the 92nd Annual Meeting of the Transportation Research Board, Washington, DC, USA, 13-17 January 2013.

29. Yi, Z.; Bauer, P.H. Optimization models for placement of an energy-aware electric vehicle charging infrastructure. Transp. Res. Part E Logist. Transp. Rev. 2016, 91, 227-244. [CrossRef]

30. Gnann, T.; Funke, S.; Jakobsson, N.; Plötz, P.; Sprei, F.; Bennehag, A. Fast charging infrastructure for electric vehicles: Today's situation and future needs. Transp. Res. Part D Transp. Environ. 2018, 62, 314-329. [CrossRef]

31. Xing, Y.; Ma, E.W.; Tsui, K.L.; Pecht, M. Battery management systems in electric and hybrid vehicles. Energies 2011, 4, 1840-1857. [CrossRef] 
32. Pollet, B.G.; Staffell, I.; Shang, J. Current status of hybrid, battery and fuel cell electric vehicles: From electrochemistry to market prospects. Electrochem. Acta 2012, 84, 235-249. [CrossRef]

33. Sabri, M.F.M.; Danapalasingam, K.A.; Rahmat, M.F. A review on hybrid electric vehicles architecture and energy management strategies. Renew. Sustain. Energy Rev. 2016, 53, 1433-1442. [CrossRef]

34. Lipu, M.H.; Hannan, M.A.; Hussain, A.; Hoque, M.M.; Ker, P.J.; Saad, M.H.M.; Ayob, A. A review of state of health and remaining useful life estimation methods for lithium-ion battery in electric vehicles: Challenges and recommendations. J. Clean. Prod. 2018, 205, 115-133. [CrossRef]

35. Wu, L.; Wang, W.; Jing, P.; Chen, Y.; Zhan, F.; Shi, Y.; Li, T. Travel mode choice and their impacts on environment-a literature review based on bibliometric and content analysis, 2000-2018. J. Clean. Prod. 2019, 249, 119391. [CrossRef]

36. Erdelić, T.; Carić, T. A survey on the electric vehicle routing problem: Variants and solution approaches. J. Adv. Transp. 2019, 2019, 5075671. [CrossRef]

37. Schiffer, M.; Schneider, M.; Walther, G.; Laporte, G. Vehicle routing and location routing with intermediate stops: A review. Transp. Sci. 2019, 53, 319-343. [CrossRef]

38. Artmeier, A.; Haselmayr, J.; Leucker, M.; Sachenbacher, M. The shortest path problem revisited: Optimal routing for electric vehicles. Adv. Artif. Int. 2010, 6359, 309-316.

39. Sachenbacher, M.; Leucker, M.; Artmeier, A.; Haselmayr, J. Efficient energy-optimal routing for electric vehicles. In Proceedings of the 25th AAAI Conference on Artificial Intelligence, San Francisco, CA, USA, 7-11 August 2011; pp. 1402-1407.

40. Storandt, S. Quick and energy-efficient routes: Computing constrained shortest paths for electric vehicles. In Proceedings of the 5th ACM SIGSPATIAL International Workshop on Computational Transportation Science, Redondo Beach, CA, USA, 6 November 2012; pp. 20-25.

41. Erdoğan, S.; Miller-Hooks, E. A green vehicle routing problem. Transp. Res. Part E Logist. Transp. Rev. 2012, 48, 100-114. [CrossRef]

42. Adler, J.D.; Mirchandani, P.B. Online routing and battery reservations for electric vehicles with swappable batteries. Transp. Res. Part B Methodol. 2014, 70, 285-302. [CrossRef]

43. Schneider, M.; Stenger, A.; Goeke, D. The electric vehicle routing problem with time windows and recharging stations. Transp. Sci. 2014, 48, 500-520. [CrossRef]

44. Strehler, M.; Merting, S.; Schwan, C. Energy-efficient shortest routes for electric and hybrid vehicles. Transp. Res. Part B Methodol. 2017, 103, 111-135. [CrossRef]

45. Gardner, L.M.; Duell, M.; Waller, S.T. A framework for evaluating the role of electric vehicles in transportation network infrastructure under travel demand variability. Transp. Res. Part A Policy Pract. 2013, 49, 76-90. [CrossRef]

46. Jiang, N.; Xie, C.; Waller, S.T. Path-constrained traffic assignment: Model and algorithm. Transp. Res. Rec. 2012, 2283, 25-33. [CrossRef]

47. Jiang, N.; Xie, C.; Duthie, J.C.; Waller, S.T. A network equilibrium analysis on destination, route and parking choices with mixed gasoline and electric vehicular flows. EURO J. Transp. Logist. 2014, 3, 55-92. [CrossRef]

48. Jiang, N.; Xie, C. Computing and analyzing mixed equilibrium network flows with gasoline and electric vehicles. Comput.-Aided Civ. Infrastr. Eng. 2014, 29, 626-641. [CrossRef]

49. Xie, C.; Wang, T.G.; Pu, X.; Karoonsoontawong, A. Path-constrained traffic assignment: Modeling and computing network impacts of stochastic range anxiety. Transp. Res. Part B Methodol. 2017, 103, 136-157. [CrossRef]

50. Xie, C.; Wu, X.; Boyles, S. Traffic equilibrium with a continuously distributed bound on travel weights: The rise of range anxiety and mental account. Ann. Oper. Res. 2019, 273, 279-310. [CrossRef]

51. Zhang, T.; Xie, C.; Waller, S.T. Network flows of plug-in electric vehicles: Impacts of electricity-charging price. In Proceedings of the 92nd Annual Meeting of the Transportation Research Board, Washington, DC, USA, 13-17 January 2013.

52. He, F.; Wu, D.; Yin, Y.; Guan, Y. Optimal deployment of public charging stations for plug-in hybrid electric vehicles. Transp. Res. Part B Methodol. 2013, 47, 87-101. [CrossRef]

53. He, F.; Yin, Y.; Lawphongpanich, S. Network equilibrium models with battery electric vehicles. Transp. Res. Part B Methodol. 2014, 67, 306-319. [CrossRef]

54. Agrawal, S.K.; Boyles, S.; Jiang, N.; Shahabi, M.; Unnikrishnan, A. A network route choice model for BEV drivers with different risk attitudes. Transp. Res. Rec. 2015, 2498, 75-83. [CrossRef] 
55. Xie, C.; Jiang, N. Relay requirement and traffic assignment of electric vehicles. Comput.-Aided Civ. Infrastr. Eng. 2016, 31, 580-598. [CrossRef]

56. Xu, M.; Meng, Q.; Liu, K.; Yamamoto, T. Joint charging mode and location choice model for battery electric vehicle users. Transp. Res. Part B Methodol. 2017, 103, 68-86. [CrossRef]

57. Liu, H.; Yin, W.; Yuan, X.; Niu, M. Reserving charging decision-making model and route plan for electric vehicles considering information of traffic and charging station. Sustainability 2018, 10, 1324. [CrossRef]

58. Fiori, C.; Ahn, K.; Rakha, H.A. Optimum routing of battery electric vehicles: Insights using empirical data and microsimulation. Transp. Res. Part D Transp. Environ. 2018, 64, 262-272. [CrossRef]

59. Yang, Y.; Yao, E.; Yang, Z.; Zhang, R. Modeling the charging and route choice behaviour of BEV drivers. Transp. Res. Part C Emerg. Technol. 2016, 65, 190-204. [CrossRef]

60. Prato, C.G. Route choice modeling: Past, present and future research directions. J. Choice Model. 2009, 2, 65-100. [CrossRef]

61. Fetene, G.M.; Kaplan, S.; Jensen, A.F.; Mabit, S.L.; Prato, C.G. Harnessing big data for estimating the energy consumption and driving range of electric vehicles. Transp. Res. Part D Transp. Environ. 2017, 54, 1-11. [CrossRef]

62. Jensen, A.F.; Mabit, S.L. The use of electric vehicles: A case study on adding an electric car to a household. Transp. Res. Part A Policy Pract. 2017, 106, 89-99. [CrossRef]

63. Prato, C.G.; Rasmussen, T.K.; Nielsen, O.A. Estimating value of congestion and of reliability from observation of route choice behavior of car drivers. Transp. Res. Rec. 2014, 2412, 20-27. [CrossRef]

64. Nielsen, O.A. A stochastic transit assignment model considering differences in passengers utility functions. Transp. Res. Part B Methodol. 2000, 34, 377-402. [CrossRef]

65. Bovy, P.H.L.; Bekhor, S.; Prato, C.G. The factor of revised path size: Alternative derivation. Transp. Res. Rec. 2008, 2076, 132-140. [CrossRef]

66. Louviere, J.; Hensher, D.A.; Swait, J. Stated Choice Methods: Analysis and Application; Cambridge University Press: Cambridge, MA, USA, 2000.

67. Ben-Akiva, M.E.; Morikawa, T. Estimation of travel demand models from multiple data sources. In Proceedings of the 11th International Symposium on Transportation and Traffic Theory; Elsevier: New York, NY, USA, 1990; pp. 461-476.

68. Swait, J.; Louviere, J. The role of the scale parameter in the estimation and comparison of multinomial logit models. J. Mark. Res. 1993, 30, 305-314. [CrossRef]

69. Hensher, D.A.; Louviere, J.; Swait, J. Combining sources of preference data. J. Econom. 1999, 89, $197-221$. [CrossRef]

70. Bekhor, S.; Prato, C.G. Methodological transferability in route choice modeling. Transp. Res. Part B Methodol. 2009, 43, 422-437. [CrossRef]

71. Brownstone, D.; Bunch, D.S.; Train, K. Joint mixed logit models of stated and revealed preferences for alternative-fuel vehicles. Transp. Res. Part B Methodol. 2000, 34, 315-338. [CrossRef]

72. Bhat, C.R.; Castelar, S. A unified mixed logit framework for modeling revealed and stated preferences: Formulation and application to congestion pricing analysis in the San Francisco Bay area. Transp. Res. Part B Methodol. 2002, 36, 593-616. [CrossRef]

73. Cherchi, E.; Ortuzar, J.d.D. On fitting mode specific constants in the presence of new options in RP/SP models. Transp. Res. Part A Policy Pract. 2006, 40, 1-18. [CrossRef]

74. Bierlaire, M. PythonBiogeme: A Short Introduction; Report TRANSP-OR 160706 2016; Series on Biogeme; Transport and Mobility Laboratory, School of Architecture, Civil and Environmental Engineering, Ecole Polytechnique Fédérale de Lausanne: Lausanne, Switzerland, 2017.

75. Hess, S.; Train, K.E.; Polak, J.W. On the use of a Modified Latin Hypercube Sampling (MLHS) method in the estimation of a mixed logit model for vehicle choice. Transp. Res. Part B Methodol. 2006, 40, 147-163. [CrossRef]

76. Zahabi, S.A.H.; Miranda-Moreno, L.; Barla, P.; Vincent, B. Fuel economy of hybrid-electric versus conventional gasoline vehicles in real-world conditions: A case study of cold cities in Quebec, Canada. Transp. Res. Part D Transp. Environ. 2014, 32, 184-192. [CrossRef]

77. Honda Pricelist Denmark 2019. Available online: https://www.honda.dk/cars/get-abrochure/get-a-brochure/_jcr_content/par1/richtextcolumn_62a2/par/richtextdownload_217/file.res/ Prislistepersonbilerseptember2019.pdf (accessed on 15 October 2019). 
78. Zhuge, C.; Shao, C.; Li, X. A comparative study of en route refuelling behaviours of conventional and Electric Vehicles in Beijing, China. Sustainability 2019, 11, 3869. [CrossRef]

79. Watling, D.P.; Rasmussen, T.K.; Prato, C.G.; Nielsen, O.A. Stochastic User Equilibrium with equilibrated choice sets: Part I-Model formulations under alternative distributions and restrictions. Transp. Res. Part $B$ Methodol. 2015, 77, 166-181. [CrossRef]

80. Watling, D.P.; Rasmussen, T.K.; Prato, C.G.; Nielsen, O.A. Stochastic user equilibrium with a bounded choice model. Transp. Res. Part B Methodol. 2018, 114, 254-280. [CrossRef]

(C) 2020 by the authors. Licensee MDPI, Basel, Switzerland. This article is an open access article distributed under the terms and conditions of the Creative Commons Attribution (CC BY) license (http://creativecommons.org/licenses/by/4.0/). 